\title{
Need \& Gap Analysis of Converting a City into Smart City
}

\author{
Yatin Jog, Tarun Kumar Singhal, Falgun Barot, Macneal Cardoza \\ and Deepika Dave \\ Symbiosis Institute of Telecom Management, \\ Symbiosis International University, Pune, India \\ yjog@sitm.ac.in,tarun.singhal@sitm.ac.in,falgun.barot@sitm.ac.in \\ macneal.cardoza@sitm.ac.in,deepika.dave@sitm.ac.in
}

\begin{abstract}
India is developing at a very fast pace. Urbanization in the wake of enhanced employment opportunities has put a huge pressure on the cities due to large migration of people from rural to urban areas. $31 \%$ of the population of India lives in cities. Indian cities are not ready to handle this overwhelming migration of population from villages to cities. It has put tremendous pressure on cities. There is a problem of electricity, water supply, living spaces etc.

To solve this huge crisis, smart cities are being developed. These cities are being developed to make the life of people living in these cities easier and more pleasant. There is also an added advantage of new job opportunities for the unemployed youth of the country. Hence the youth migrating from the villages of India will have equal opportunities. It will also reduce the crime rate and raise the literacy rate in the country. All the technological assets of the city will be utilized ns a better way. This will create a better tomorrow for the citizens and also create a better environment for the people to live in. However, there is still a dilemma that on what 'key indicators' should a city be converted into a smart city.

In this research paper, we have discussed various services as one of the 'key indicators' that make a city 'smart'. For this we have considered different cities across the world and chosen the services that are common to all these cities, so that this concept can be applied to future smart cities in India.
\end{abstract}

Keywords: SMART, Smart City, Smart Services, Smart Solutions

\section{Introduction}

Smart city is visualized differently by different stakeholders for the lack of a standardized or a universal definition. The conceptualization of smart city, therefore, varies from city to city and country to country, depending on the level of development, willingness to change and reform, resources and aspirations of the city residents. A smart city would have a different connotation in India than, say, Europe. The following statements and views reflect the understanding of smart cities in layman terms:

- A city can be deemed as a smart city only when it uses technology for the betterment of the standard of living of the people. The city should be able to utilize all means of communication and technology to combat future problems as well as current issues. Large amount of data has to be analyzed on a day to day basis to address day to day issues.

- A city that follows at least 5 out of 8 of the following parameters, viz. smart energy, smart building, smart mobility, smart healthcare, smart infrastructure, smart technology, smart governance and smart education \& smart citizen, will be deemed as a smart city. 
- A city where there is an interaction between people and machines for the various purposes like fulfilling of the economic and social needs of society. This has to include use of technology in various fields like energy, materials, services and financing.

- A city that uses Information and communication technologies (ICT) to manage the city's assets which include, but not limited to, local departments information systems, schools, libraries, transportation systems, hospitals, power plants, water supply networks, waste management, law enforcement, and other community services, can be called a smart city.

- A smart city is essentially an urban region which uses highly advanced technologies in the overall infrastructure, sustainable real estate, communications and market viability. These cities use Information and communication technologies (ICT) extensively for providing services to the residents.

- A city that uses smart technologies (IOT) to improve the quality of life of the residents of the city and also to build a sustainable and clean environment for the residents of the city can be termed as a smart city.

- A highly advanced urban region that uses manpower and ICT for advancements in key areas like economy, mobility, environment, people, living, and government.

\section{Current Status of Smart Cities and Progress so Far}

The Indian government has planned to establish/convert 100 smart cities in India within the five years duration period (FY2015-16 to FY2019-20) (MOUD, Smart City mission statements \& guidelines, 2015). In April 2015, the Union Cabinet of India approved 100 cities for the Indian smart cities program. The development of the cities will be done in the form of four strategy implementation processes namely retrofitting, redevelopment, green field development \& pan-city development. The government has a smart city selection process based on which these cities have been shortlisted fulfilling different criteria. Further scaling this down, 20 cities have been chosen for the next round of funding. As predicted by the experts, the smart city prospects in India offer $\$ 1.5$ trillion market opportunity from global players (UKTI, 2015).

To select the cities under the smart city program, the individual states \& Union Territories were asked to nominate the names of cities for the 'Smart City Challenge Competition' round from which the 20qualified cities would be funded approx. $\$ 10 \mathrm{mn}$ each year for the coming five year period (FY2015-16 toFY2019-20) (UKTI, 2015). Some of the key parameters that were taken into consideration for evaluation are - existing service levels, institutional systems and capacities, self-financing capabilities and past track record of reforms. Some of the criteria for short listing these cities are as listed in the below table: 


\begin{tabular}{|c|l|c|}
\hline Sr. No. & \multicolumn{1}{|c|}{ Criterion } & \multirow{2}{*}{ Weightage in terms of percentage } \\
\hline 1 & Implementation Framework & \multirow{2}{*}{$30 \%$} \\
\hline 2 & Feasibility & \\
\hline 3 & Cost-effectiveness & $20 \%$ \\
\hline 4 & Result Orientation & $16 \%$ \\
\hline 5 & Citizen Participation & $10 \%$ \\
\hline 6 & Smartness Of Proposals & $10 \%$ \\
\hline 7 & Strategic Plans & $5 \%$ \\
\hline 8 & Vision \& Goals & $5 \%$ \\
\hline 9 & Evidence-Based City Profiling & \\
\hline 10 & Key Performance Indicators & $4 \%$ \\
\hline 11 & Process Followed & $\mathbf{1 0 0 \%}$ \\
\hline \multicolumn{2}{|l|}{ Total Percentage of the parameters } & \\
\hline
\end{tabular}

\subsection{Stage - 1 of Selection Criteria Process}

Every state had to nominate the cities, which had the potential to qualify as future smart cities as per the government. The centre then shortlisted 100 cities based on the nominations from every state.

- Current Service Levels: This criteria takes into consideration the current service levels as compared to the 2011 Census, an integrated operational online grievance redressal system, at least first public newsletter publication\& the details of the online publication of municipal budget expenditure of the last two financial years on the website.

- Institutional Systems \& Capacities: The imposition of penalties for delays in the service delivery $\&$ the check on the improvement in the internal resource generation from past three years.

- Self-Financing Capacity: The payment of salaries by the urban local bodies up to the last month of FY 2014-15, the auditing of accounts up to FY 2012-13, internal revenue budget contribution for FY 2014-15, contribution by the percentage of establishment \& maintenance cost of water supply through user charges in the FY 2014-15.

- Past Track Records: Percentage of completion of JNNURM projects sanctioned till 2012, percentage of level city reforms accomplished under JNNURM \& the extent to which the capital expenditure is met from the internal sources.

List of selection criteria with the weightage in terms of points for stage -1 selection process:

\begin{tabular}{|c|l|c|}
\hline Sr. No. & \multicolumn{1}{|c|}{ Criterion } & Weight in terms of points \\
\hline 1 & Current Service Levels & 25 \\
\hline 2 & Institutional Systems \& Capacities & 15 \\
\hline 3 & Self-Financing Capacities & 30 \\
\hline 4 & Past Track Records & 30 \\
\hline
\end{tabular}

\subsection{Stage -2 of Selection Criteria Process}

The stage -2 focuses on the 100 smart cities selected in the stage -1 process which were further evaluated by prioritization $\&$ hence selected for the purpose of financing. 20 
cities out of 100 were selected which will be financed during this financial year. The remaining cities were asked to fix the loopholes \& hence be ready for the next two rounds of the competition in which $40 \& 38$ cities would be selected respectively as per the Apex Committee in MOUD (Desk, 2016). List of selection criteria with the weightage \& subparameters for stage -2 selection process:

\begin{tabular}{|c|l|l|c|}
\hline Sr. No. & Criterion & Sub parameters & Weight in points \\
\hline 1 & \multirow{2}{*}{ Evaluation by city } & Implementation Credibility & \multirow{2}{*}{30} \\
\cline { 3 - 3 } & & Vision \& strategy & \multirow{2}{*}{} \\
\hline 2 & \multirow{2}{*}{\begin{tabular}{c}
\multirow{2}{*}{ Evaluation by } \\
Proposal
\end{tabular}} & Proposal Impact \\
& \multirow{2}{*}{$\begin{array}{l}\text { Cost structure of the Plan } \\
\end{array}$} & Innovation \& Scalability & \\
\cline { 3 - 3 } & & Process undertaken & \\
\hline
\end{tabular}

Urban Development Minister has proposed the below list of 98 smart cities of which Uttar Pradesh \& Tamil Nadu had the largest share of 13 \& 12 cities respectively. The list consists of 24 capital cities, 24 business \& industrial centres, 18 tourist\& culture influences cities, 5 port cities \& 3education \& health care hubs (JEELANI, 2015). These cities were flourish into smart cities 5 years down the line. The list of 20 cities selected in the first stage of 98 are as listed below. (Desk, 2016).

\begin{tabular}{|c|l|l|c|l|l|}
\hline Rank & $\begin{array}{l}\text { State/Union } \\
\text { Territory }\end{array}$ & Selected Cities & Rank & $\begin{array}{l}\text { State/Union } \\
\text { Territory }\end{array}$ & $\begin{array}{l}\text { Selected } \\
\text { Cities }\end{array}$ \\
\hline 1 & Odhisa & Bhubaneshwar & 11 & Madhya Pradesh & Indore \\
\hline 2 & Maharashtra & Pune & 12 & - & New Delhi \\
\hline 3 & Rajasthan & Jaipur & 13 & Tamil Nadu & Coimbatore \\
\hline 4 & Gujarat & Surat & 14 & Andhra Pradesh & Kakinada \\
\hline 5 & Kerela & Kochi & 15 & Karnataka & Belagavi \\
\hline 6 & Gujarat & Ahmedabad & 16 & Rajasthan & Udaipur \\
\hline 7 & Madhya Pradesh & Jabalpur & 17 & Assam & Guwahati \\
\hline 8 & Andhra Pradesh & Vishakhapatnam & 18 & Tamil Nadu & Chennai \\
\hline 9 & Maharashtra & Solapur & 19 & Punjab & Ludhiana \\
\hline 10 & Karnataka & Davangere & 20 & Madhya Pradesh & Bhopal \\
\hline
\end{tabular}

\section{Global smart cities \& its features}

When it comes to the term smart city India is at a nascent stage and so far only the selection of the probable smart cities has been proposed. But across the globe unlike India there are several cities which have been successfully implementing various smart services and projects. Although none of the cities can be categorized as a fully-fledged smart city but most of them are very close to becoming ones. Following are the few global cities to which the rest of the world look upon as smart cities:

\subsection{Amsterdam}

The capital city of Netherlands is on a mission to turn itself into the world's smartest city. (Larson, 2015) The city is known for its smart urban planning and transportation services. Some of the key smart features of the city are: (Larson, 2015) 
- Smart parking and Smart traffic management

- Smart street lighting

- Smart energy meters at households ( to check and reduce energy consumption)

- Free Wi-Fi access points and devices everywhere in the city

\subsection{Barcelona}

The Spanish city Barcelona can be considered as an ideal smart city. The city has implemented a lot of smart features which no other city has. Following are the smart projects the city is currently running:

- Smart traffic light

- GPS and traffic management software

- Smart electronic transport bus network(solar operated touch screens and bus shelters)

- Smart waste management systems

- Smart street lights

- Sensor technology for irrigation

- Smart solar energy systems for water heating etc.

- Smart urban mobility using mobile apps(for navigating in the city)

\subsection{Stockholm}

Stockholm is the capital of Sweden and is considered as one of the world's most fibre connected cities. The Stockholm's fibre network is being provided and maintained by Stokab. It is a company which is owned by the City Council of Stockholm. Some of the smart city features which the city has implemented are as follows:

- Green IT strategy

- Smart traffic monitoring

- e-services (minimizing paper usage)

- Most connected city (fibre network everywhere for computer traffic, TV, telephony etc.) (The Smart City, 2016)

\subsection{New York}

New York is said to be a city of innovative solutions. Traffic once used to be a major challenge for the city with about 3,774 deaths on New York City Streets Between 2001 and 2009. The Department of Transportation (NYCDOT) of the city of New York made use of smart techniques of data modeling to analyze and monitor patterns of traffic and pedestrian as well as for managing traffic efficiently. (Smart Cities Challenge, 2016) Other smart features in the city are also focused on improving its citizens' lifestyle and safety and are as follows:

- Smart traffic management

- Smart meters

- Building automation and control solutions(security, fire safety, alarms, lighting, gas and smoke detection

- Smart energy management(Smart grid, smart water meters, smart solar energy solutions, smart electricity meters)

- Free public Wi-Fi network

- GHG emissions tracking 


\subsection{Toronto}

The city of Toronto has also focused on providing smart solutions to ensure public convenience and safety. The major smart features of the city are:

- Smart water meters

- Building energy efficiency

- GHG emissions tracking

- Public safety module using CCTV and real-time sensors

- Smart traffic management systems (Peacock, 2015)

\subsection{Singapore}

Singapore has been named very recently (May 2016) by the market research firm Juniper Research as the world's smartest city. The city has scored most in its public transportation systems. The smart features of the city are:

- Smart transportation

- Smart parking

- Smart traffic management

- Sensors and camera for smart waste management

- High speed wireless connectivity and smart mobility

- Fibre connectivity (Buntz, 2016)

The above cities are not the only smart cities in the world. Apart from the above mentioned cities there are cities like London, San Francisco, Dubai, Oslo, Chicago, Tokyo, Hong Kong, Auckland, Sydney, which are implementing and successfully running a number of smart city projects.

\subsection{Auckland}

Auckland is one of the major cities in New Zealand. It has a huge problem of traffic and also parking. Auckland is one of New Zealand's largest urbanized city and therefore faces challenges for providing enough space and in keeping the busy traffic moving. Services offered:

- Smart traffic management

- Smart governance

- Smart lighting

- Smart environment

- Smart airways

\subsection{Dubai}

The Dubai Municipality and the Dubai Smart Government are working round the clock to realize the vision of transforming Dubai into a complete Smart City. Dubai's roadmap from five main aspects towards achieving the smart city includes corporate framework, scientific research, development, awareness and stimulus program. Services offered:

- Smart transportation system (by deploying traffic sensors, launching mobile traffic apps, and also looking at the introduction of driverless vehicles in the city's ecosystem).(Achkhanian, 2016)

- Smart urban landscape project.

- Smart energy grid

- Smart government e-services 


\subsection{Oslo}

Oslo is the capital of Norway, it also has the largest population. The Oslo region is one of the fastest growing regions in Europe. For such a growing city, it requires the implementation of many smart solutions to deal with challenges and create exciting opportunities for its citizens. Services offered:

- Smart street lighting system

- Smart decarburization

- Smart parking

- Smart LED lighting

- Broad sensing network for monitoring traffic levels

- Smart grid system

\subsection{Hong Kong}

In recent years, the Hong Kong Special Administrative Region (HKSAR) Government has been ensuring the development of Hong Kong as a regional data centre with initiatives to establish an Internet exchange centre and assume a leading position in cloud computing service in the region, thus laying the foundation for Hong Kong to develop into a regional Internet hub. (Central Policy Unit, 2015) Services offered:

- Smart mobility

- Smart environment

- Smart governance

\subsection{London}

Considered as one of the biggest cities in Europe, London implements smart solutions to meet its challenges using its robust and unmatchable communication, transport, and business connections. Smart London is all about making the capital function better and making its citizens grow with innovative ideas. Services offered:

- Smart enterprise(Government of UK)

- Smart safety

- Smart health(Government of UK)

- Smart transport

- Smart environment

\subsection{San Francisco}

San Francisco has been very much a part of the International Network of Smart Cities since 2011. The city has also been sharing its best practices with sister cities like Paris and Barcelona. The government of San Francisco has leveraged technology to expand transportation system, devise more efficient building operations, reduce energy usage and streamline waste management system for achieving objectives of greening the city while ensuring better mobility. Services offered:

- Smart shipyard implementation using GPS enabled technology

- Smart building

- Smart governance and Smart waste management

\subsection{Sydney}

Sydney is the most populous city of Australia. Sydney enjoys the credits of inventing Google Maps and typical Wi-Fi technologies. Sydney uses London-style open payment 
technology. Sydney is a very sociable place, so Internet of Things (IoT) has the capacity to facilitate easier, faster and fluent networking, business and meetings. Services offered:

- Smart parking

- Smart grid

- Smart retail

\section{List of Services in a Smart City}

\subsection{Smart Energy Meter}

The Smart Energy Meter is the latest digital gas \& electricity meter which can digitally rate the consumption and send it to the energy supplier on real time basis. These meters are replacing the traditional meters being used currently and helping in more accurate energy readings (Smart meters /What is a smart meter and how do they work, 2016). These meters come with monitors which help in more accurate monitoring of the energy consumption. The kWh \& cost wise energy consumption can be known to the customer \& hence they can modify their energy usage patterns by switching appliances which consume more electricity or gas and focus on savings.

The smart meter uses the IOT technology with the help of which both the users \& the suppliers can get to know about the energy readings simultaneously \& hence help in better communication between the two parties (Smart Grid, 2014). The consumers no longer have to wait in queues or wait for the supplier to come to your premises and realize the bill amount. The customers can directly pay via the energy portals that their suppliers manage online or they can directly pay via the payment merchants which the suppliers are tied up with. Also, there can be various options from which the customers can pay -i.e., via mobile, computers, other various payment options, etc.

Benefits

- Accurate billing system

- Better understanding of the energy usage patterns

- Ease in energy switching

- Understand the customer usage patterns from the supplier's side

- Various tariff options available based on the energy consumption

Vendors

Trillion | Silicon Labs | Tech Mahindra | Kamstrup | Maven Systems | Capgemini | Siemens | Schneider-Electric |EDMI | IBM

\subsection{Smart Energy Grid}

The smart grid is an evolved electricity network based energy providing service that manages electricity demand with new communication \& control capabilities of the $21^{\text {st }}$ century using computer based remote control \& automation. The system encompasses the two way communication technology from the suppliers to the consumers and vice versa in which the consumers act as the prosumers of electricity (Smart Grid, 2014). Smart Grids will help mitigate the carbon footprint and help in providing efficient electricity to meet the required demands, increase the reliability and maintain the quality of power supplies, power of backward compatibility with the existing infrastructure as well as long lasting technology standards (IEEESmart Grid, 2015).

Benefits

- Better control over energy costs from the customer's perspective \& more reliable energy supply 
- Reduction in the peak demand with integration of renewable sources with the grid in power supply, reduced $\mathrm{CO} 2$ emissions \& other pollutants

- Major focus on smart grid implementation is to cater to capacity, efficiency, reliability \& sustainability

- Interoperability with the communication standards and integration with the renewable as well as non-renewable power generation sources simultaneously

- Automatic detection of the failure and computerized self-healing mechanism

- Enhanced customer participation in supplying back the electricity and hence following the prosumer concept

- Better load handling, demand response support and decentralization of power generation from multiple sources as per the capacity \& demand

Vendors

ABB | Cisco | Schneider-Electric | Intron | Siemens | Tendril | Opower | Aclara | Silverspring |Honeywell

\subsection{Smart Street Lighting}

Street Lighting solutions for the modern world are replacing the basic functionalities of the LEDs in providing light in public parks, parking and roads to enhance the pedestrian safety, providing more energy efficient solutions and incorporating wide range of IoT applications integrated in one lamp post(www.echelon.com). Also, street lighting solutions from big players follow the open network standards so as to maintain the interoperability and work with different horizontal verticals in terms of component \& technology functionalities.

The transformation in street lighting systems is taking a positive shape as most of the private solution providers in metro cities have started to implement the latest smart street lighting solutions. These no longer would require replacing the existing legacy network of street lights as these new solutions have majorly deployed in the green field colonies \& townships. So the government needs to think about solutions which can work on their legacy networks in some areas while the newly smart cities need to incorporate the totally new methodology of street lighting systems.

Benefits

- $24 * 7$ power control with the help of automated computing and software control mechanisms

- Integration of sensors like air, gas and temperature along with the lamp mask can enhance the functionality and help in monitoring the pollution levels

- Integrating cameras powered by the street light circuits can help in increasing public safety \&empower the video based applications

- Controlling the digital advertising panels and providing electric vehicle charging functionalities

- Cost and energy efficient control systems as compared to the legacy networks while reducing the energy consumptions

- Identification of the individual lamp failure with full remote control of the network

- Local/remote and secured web access to the street light monitoring web applications along with data collection \& web services

Vendors

OSRAM | Tvilight | SilverSpring | Echelon | Billion | InteliLight | GE Lighting | Maven Systems | Verizon | TelensaPLANet 


\subsection{Smart Parking}

One of the biggest difficulties any developing or developed country faces is parking for vehicles. India, too, is witnessing the increasing number of private vehicles creating chaos for the traffic management systems in India. Implementing smart parking solutions would create many opportunities in terms of efficient parking management as well as ease for the customers in utilizing the space for parking.

Metros are getting flooded with cars and every multistory building is facing the challenge of finding the best parking solution for its occupants. With various vendors across the globe providing smart parking solutions, this difficulty has started mitigating but is not in sync with the increase in the vehicles. Implementation seems to be a challenge as most of these solutions need to be retrofitted. Nevertheless, greenfield building and flats as well as the malls have been implementing smart solutions which is also in less numbers. Hence, there is a very desperate need for these smart parking solutions to be effectively implemented.

\section{Benefits}

- Integration with the IoT technology \&cloud based solutions for automated remote monitoring

- Accurately predicting\& sensing the available space for the parking in real time based on which the users can be notified the exact parking available (Aditya Basu, 2014)

- Two way communication to ensure that there is no communication gap between the parking provider and the customer

- Reduced costs and manpower deployment as the process is happening automatically

- Highly secure vehicle facilitating individual monitoring of the vehicle by the owner

Vendors

SmartParking | Siemens | CivicSmart | Cisco | Sterlite | Amricon | Intercomp

\subsection{Smart Building}

Making homes, commercial buildings, malls and hospitals better by automating and integrating various small systems which could help ease the lifestyle $\&$ working conditions of the people within the premises of the building falls under the scope of an advanced automated \& intelligent building. The aim of a smart or intelligent building is to minimize the use of resources \& make services like fire \& safety, alarm systems, lighting control, detection of leakage - gas, water $\&$ many such services accessible instantly $\&$ during the time of necessity (Honeywell | Building Solutions).

The major controller or driver of all these systems is the Building Management Systems (BMS) and Building Automation \& Control Systems (BACS). With the incorporation of these systems, it is pretty accurate and easy to manage different services within a building. These systems come with latest IoT technology integration and are very powerful (Intel, 2014). It helps majorly in reducing the manual control over almost all the systems accessible manually and can be controlled remotely. These include smart meters, water and gas detectors, automated lighting control systems, pollution detectors and various types of sensors for multiple purposes.

\section{Benefits}

- Automated monitoring \& control from a single platform which can be done remotely or within the premises.

- Energy optimization and increase in the operational efficiency 
- Increased safety as well as security with greater comfort and ease in working conditions

- Systems are easy to deploy and lower life-cycle costs

Vendors

Honeywell | Intel | Cisco | Siemens | CommScope | IBM | Schneider-Electric | ThingWorx | JohnsonControls | Geecomms

\subsection{Smart Waste Management}

Waste management has always been a big problem in urban as well as rural areas. The authorities always look for ways to handle the large amount of waste that is produced in cities. Waste is generally collected from households, factories, workshops etc. and dumped in large dumping grounds which are located on the outskirts of the cities. India has a huge population and it is growing by the day. As per the census of 2011, India has a population of 102 billion. The amount of waste generated by such a massive population is huge. This fact makes smart waste management a necessity.

Smart waste management is the collection and management of the solid waste collected from various sources like households, commercial buildings, hospitals, slaughter houses, public places, restaurants etc. The use of technologies like RFID disposal tag, sensor containers and vacuum containers, which provide real-time fill measurement of solid municipal waste will cause a great deal of relief from the traditional dumping of waste in dumping grounds. The main focus should be on recycling. The recycle policy will be the main motto of smart waste management. (Urbiotica)

Benefits

- Reduction in time and energy required to provide waste management services(Urbiotica)

- Reduce the amount of waste created

- Make the environment safe

- Reduce the spread of diseases

- Cost reduction and resource optimization

Vendors

Urbiotica | Enevo | Smartbin | MOBA Mobile Automation MG | BreSMARTWaste | Grid Waste |Compology| Bigbelly | Waviot waste montoring | Ecube Labs

\subsection{Smart Pollution Detection}

Pollution is something that has been haunting urban areas in recent years. Progress has always come with a cost and the environment has always being paying for it. Pollution causes harm to us humans and other life forms on a great deal, hence smart pollution detection systems are the need of the hour.

Smart pollution detection can detect the level of pollutants in the air or any other medium for that matter. As per the level of pollution, smart solutions can be devised to curb this pollution.

The objective of smart pollution detection is to use IoT for the detection of pollution in a specific area(Marina Sruthi.M, 2016). A number of devices are connected to the internet. These devices keep updating the amount of pollutants say, Carbon Monoxide to the cloud. The data collected from various devices in the same area can be collected and the pollution level in that specific area can be estimated.

\section{Benefits}

- Reduction of pollution (air, water and noise) 
- Cleaner environment

- Reduction of greenhouse gases

Vendors

Breeze | Breezometer | Understory | Aclima | DasBox | Lapka Inc. | Cumulonimbus

\subsection{Smart Forest Fire Detection}

Forest fires have caused irreparable losses of precious human lives and properties. In the summer of 2007, there were more than 80 people died in Greece and 670,000 acres $(2,711 \mathrm{~km} 2)$ burned because of fires. The same year in California, 500,000 acres $(2,027$ $\mathrm{km} 2$ ) were devastated by the flames, causing at least 14 fatalities. These forest fires once started are very difficult to extinguish, and soon spread across the region causing devastation along its path.

The solution to this problem is a wireless sensor network, a communication network and a reception centre. The wireless sensors will detect the rise in the temperature and also detect the rise in the levels of different gases like Carbon Monoxide, Carbon Dioxide, Nitrogen Dioxide etc. and alert the reception centre. Also satellite images of the particular area can be obtained which will point out the exact location of the fire.

Benefits

- Reduction in loss of lives

- Reduction in loss of property

- Fires can be controlled in the budding stage

- Air pollution control

Vendors

Libelium| Crossbow Company

\subsection{Smart Water Management}

Water is one of the most precious resources required to sustain all forms of lives. Water as an important resource needs to be conserved. Hence smart water management plays an important role in the development of a better and sustained tomorrow.

Smart water management helps farmers irrigate crops in an effective manner while helping in landscaping. The most important function of water management is the conservation of water. Effective management of water is also an important role played by the smart water management system.

\section{Benefits}

- Better utilization of water resources

- Conservation of water

- Better irrigation

- Effective landscaping

- Reduction of pressure of the Earth's water resources

Vendors

Rachio|Valor water aanalytics|Watersmart software |Sensus| SIWA Water management

\subsection{Smart Transportation}

A huge number of people travel on a daily basis putting huge pressure on the transportation system. Many people tend to lose their lives in the process also. Transportation not only includes road transport, but also sea and air transport. Also 
management of logistics is a big problem for companies. Smart transportation will prove to be a boon to such organizations. (LAM)

Smart transportation helps enterprise and people to improve efficiency during the journey from varied data acquisition, analysis, and precise predictions. Furthermore, with real-time streaming NVR (Network Video Recorder) logs, critical moments can be recorded when accident happens, therefore enhancing safety of drivers and passengers on the move. (LAM)

\section{Benefits}

- Lesser accidents

- Lesser pressure on transportation systems

- Better managed transportation

- Better productivity

- Healthier environment

Vendors

IEI integration corp. |Zagster|Yunmake|Mojio|Shuttl|Vinli|ather Energy |Zubie|Bridj

\subsection{Smart e-health}

The IoT concept enables the use of electronic devices to capture or monitor data. This concept can be implemented in the healthcare industry. Connected electronic devices can be made available to patients reducing the need for a direct patient-physician interaction. There are various forms of E-health such as electronic health records, Virtual health care teams, e-Prescribing, m-Health, Tele-Health, Telemedicine, Medical research using Grids and Healthcare Information Systems, Consumer health informatics (eHealth, 2016). Therefore, E-Health gives the opportunity to enhance healthcare services by utilizing information technology and wireless communication systems, Internet, interactive TV, remote monitoring and voice response systems, CD-ROMs, DVD-ROMs. Healthcare wearable's are becoming widely used in the e-health industry. It is expected that the number of smart wearable's shipped to the end users would reach 130 million by 2018. Smart watches, fitness bands, Google glass, knee braces, smart contact lenses etc., are being used as wearable's in the e-healthcare sector. (Kosir, 2015)

\section{Benefits}

- Real time monitoring of health of patients suffering from chronic diseases

- Reduction in the need for direct patient-physician interaction

- Enhanced health-care quality because of technological improvements

- Easy storage of past records and health related data

- Faster aid in case of emergency due to connected systems

\section{Vendors}

Google|Carestream|AirStrip|AliveCor|Apple|Athenahealth|AT\&T|BostonScientific|Cardio Net|Cerner|Epocrates|Fitbit|Honeywell|Jawbone|MotionComputing|Nike|Qualcomm|Sanofi |Telcare| Zephyr Technology(Visiongain, 2015)

\subsection{Smart Governance}

Governments of countries seek to promote growth and strengthen the economy through improved governance, modernization and public expenditure. SMART Governance or egovernance is about making use technology to support better planning and decision making to improve the ways in which public services are delivered. Using smart governance the government can leverage ICT in developing single and centralized access 
points so that citizens can access government services like bill payments, tax payments, application for new connection, birth/death certificates etc.

\title{
Benefits
}

- Speedy Access: Access to government services used to be very cumbersome with large waiting queues. But with the help of government portal citizens can avail those services faster and seamlessly.(JOSHI, 2008)

- Cost-Reduction: Paper-based communication needs a lot of paper, stationary, printers, computers, etc. which amounts to huge expenditure. E-governance makes services cheaper saving a lot of money for the Government.(JOSHI, 2008)

- Transparency: The citizens will have access to all the information anytime they want to. Existing processes might give ways to the government to conceal some of the information from the public but once the information is made available online it can eliminate the possibilities of hiding any information.(JOSHI, 2008)

- Accountability - Once the governance processes become transparent the Government automatically becomes more answerable to its citizens.(JOSHI, 2008)

\author{
Vendors \\ Most of the E-governance models follow PPP (Public Private Partnership) \\ model(E-governance,2016) Technology companies:NISG (India) |TCS|L\&T \\ Infotech|Infosys|Wipro|CSC|FNPL|IAP corp|Consulting \\ Companies:EY|PWC|Deloitte|Mckinsey|Sterlite
}

\subsection{Smart Agriculture}

Smart agriculture is seen as one of the important smart city feature and the IoT is a key enabler of smart agricultural solutions. Agriculture today faces challenges like irrigation shortage, limited land availability, increasing consumption, difficulty in managing costs. New and innovative IoT applications can address these issues while increasing sustainability of agricultural production. Remotely monitored sensors can be deployed that can detect moisture levels of the soil, growth-stages of the crop, any infection developing in the crop, livestock feed levels etc. Also IoT enabled devices can remotely control and manage harvesters and irrigation equipment and using artificial intelligence based analytics combined with other information, such as weather decision making can be improvised.(Smart Agriculture)

\section{Benefits}

- Enable farmers to easily track data and take appropriate prior action to improve productivity

- Utilize the limited land availability and irrigation facilities with maximum efficiency

- Pest control, Manure requirements etc. can be done based on real time data

- Highly precise farming methods can help reduce wastage of resources

Vendors

North America is pioneer in implementing Smart agriculture and the concept is at a nascent stage in the rest of the world. Therefore major vendors are from North America are:

Anemon (Switzerland)|eCow (UK)|Medria Technologies|Deutsche Telekom|Ag Junction (U.S.)|Deere \& Company (U.S.)| Raven Industries Inc. (U.S.) | Trimble Navigation Ltd. (U.S.)| AGCO Corporation(U.S.)|SST Development Group, Inc. (U.S.)|SemiosBIO Technologies Inc. (Canada) | VodafoneGroup(Guerrini, 2015) 


\subsection{Smart Contactless Payments}

Contactless payment systems make use of technologies like RFID (Radio-Frequency Identification) or NFC (Near Field Communication)for carrying out secure payments. The antenna and the embedded chip enable the consumers to wave their cards, fobs, or handheld device against a reader at the POS(point of sale) terminal from a distance. Customers can use debit cards and credit cards, smart cards, key fobs or other devices like smartphones to make the payments. The point of sales needs to be equipped with payment systems which can accept all forms of cards and handheld devices irrespective of the vendor.

\section{Benefits}

- Faster: Transactions are faster as compared to conventional cash payments, debit or credit card purchase because it typically does not require signature or PIN verification.(Contactless Payments)

- Secure: Contactless cards and devices are incorporated with many layers of security. Contactless works while a card or device is a few centimeters away from the terminal and this makes it apparently impossible for any details to be intercepted while using it.

- Convenient: Customers need not carry cash all the time(The benefits of Contactless)

Vendors

Contactless readers: ViVOtech|OTI|Verifone| Contactless POS systems: VeriFone |IBM|Hypercom|Ingenico|Nurit|Lipman|Micros|Radiant|

\subsection{Smart Logistics}

Smart logistics involve the use of ICT in the planning and control of supply chain management processes. Smart logistics features include the use of telematics for real time tracking and tracing the vehicles carrying the freight, linking SCM data to analytics tools to understand about the real time relationship between real-world shipments/orders and website traffic, using technologies like RFID tags and systems like bar coding and GPS tracking to track inventory at various stages of the supply-chain of the logistics in the warehouses, using smart packaging which responds to the stimuli of touch by consumers or sense if the product shelf life is over or may also provide security from theft by lighting up.

\section{Benefits}

- Easy to analyse customer buying patterns and make proactive decisions of managing supply based on demand

- Reduced time of delivery and overall improved and secure logistics services

- Reduced inventory and warehouse cost

- Reverse logistics are easier to manage.

Vendors

T-systems|Hitachi (transport system)|CGI group (UK)|AirIQ|Fleetmatics|Trimble(TOP 10 GLOBALCOMMERCIAL TELEMATICS COMPANIES, 2016)

\subsection{Smart Retail}

Retail operations have ubiquitous presence in all aspects of our lives. Retail stores are spread everywhere and people visit retail stores very frequently. Hence for a city to be smart, retail is one of the major services that should evolve into smart retail. 
Smart retail includes accelerating the time to solution deployment and making cost saving easier, increasing the efficiency of processes, and also managing the inventory in a better way. Connection of tens, hundreds, even thousands of endpoints, from inventory RFID tags to digital displays to smart shelves, and manage them all from a single interface(Intel). Smart retail also includes keeping valuable customer data safe with the help of tokenization.

\section{Benefits:}

- Process efficiency

- Safety and security(HCL Technologies, 2016)

- Better inventory management

- Better store management

- Real time monitoring POS peripherals, POS terminals etc.

- Optimize supply chain

- Balance profitability and value to the customer(HCL Technologies, 2016)

Vendors:

HCL | Intel | Smart Retail Solution | IBM | IEI Solutions | NEC Corporation of America | KosakuraSmart Retail Solutions | Cisco | Fujitsu | SAP |

\subsection{Smart Vehicles:}

Smart vehicles can be considered as one of the important enabling technologies for more efficient and sustainable transportation systems. Most electric vehicles have been now integrated with smart vehicle features. The key features that a small vehicle should have are: Intelligent navigator, smart charging, Laser radar and vision to distinguish between objects (sign boards, other vehicles etc.), anti-lock braking systems (How the Smart Car Works), Tire pressure monitoring system, Smart airbags, Integration with smart phones, GPS navigation and connectivity with other vehicles. Driverless cars are another remarkable development in the field of smart vehicles

Benefits:

- Smart features included in smart vehicles will assist to minimize road accidents.

- Increase the safety of the drivers and co passengers.

- Improve operational efficiency

- Convenience and comfort due to automated systems.

- Connected vehicles will assist in traffic management and communicating preventive warnings.

- Linking to homes, offices, and other buildings by integration of the smart vehicles into energy monitoring systems or home alarms.

- Transportation of goods by vehicles via well-delineated routes.

Vendors:

Google| SMART (Daimler AG) |Tesla |QNX| Cisco systems| Delphi |Codha Wireless| Autotalks|Mobileye |COVISINT| (TANNERT, 2014) 


\section{Conclusion}

India as the $2^{\text {nd }}$ most populous country and almost always inundated with huge religious/social/sectoral diversities has not been able to demonstrate its potential in terms of quality of living to the world. Any kind of development that has taken place in the country is dwarfed by the ever growing need and demands of this mammoth population.

Though India is developing fast, it still needs to tackle the issue of urbanization on a wider scale. Failed attempts in urbanization will pose serious impediments in growth of our economy and will possibly turn away investment opportunities as well. Seemingly distant, but creation of smart cities can create an eco-system facilitating good quality of life for residents, reliable opportunities for residents in education, healthcare, transportation, governance etc and favorable financial model for service providers.

It is widely recognized that technology can play the role of a big leveler providing equal opportunities to the disadvantaged sections of the society. We feel that smart cities could just be that leveler where every resident will be able to utilize and appreciate quality services without having to shell out exorbitant money.

In this research paper, we have talked about various key services of smart cities operational across the world with their indigenous achievements. However, we feel that no smart city model being practiced elsewhere in the world should be replicated in India blindly. Different services that have been put to use globally can however guide Indian smart cities on their path towards development.

We should also do away with "ONE SIZE FITS ALL" mindset and should critically evaluate every smart city proposition with rigorous analysis and decision matrices duly supported with broad forecasting features. Even if we come to consensus with respect to suitability of a proposed smart city model in Indian context, still we should check the grit and sustainability of the said smart city when its put to test against the onslaught of population that has been a huge problem for the country.

\section{References}

[1] Smart Grid. (2014). Retrieved from energy.gov: http://energy.gov/oe/services/technologydevelopment/smart-grid.

[2] IEEE Smart Grid. (2015). Retrieved from smartgrid.ieee.org: http://smartgrid.ieee.org/about-ieee-smartgrid.

[3] eHealth. (2016). Retrieved from Wikipedia, the free encyclopedia: https://en.wikipedia.org/wiki/EHealthSmart Cities Challenge. (2016).

[4] Smart meters | What is a smart meter and how do they work. (2016, '). Retrieved from uSwitch.com:https://www.uswitch.com/gas-electricity/guides/smart-meters-explained/\#step1.

[5] The Smart City. (2016). Retrieved from http://international.stockholm.se/city-development/the-smartcity/.

[6] TOP 10 GLOBAL COMMERCIAL TELEMATICS COMPANIES. (2016, May 18). Retrieved from http://www.technavio.com/blog/top-10-vendors-global-commercial-telematics

[7] Aditya Basu. (2014). Happiest Minds - Smart Parking. Retrieved from Happiestminds.com:http://www.happiestminds.com/whitepapers/smart-parking.pdf.

[8] Buntz, B. (2016, May 18). The World's 5 Smartest Cities. Internet of Things Institute.

[9] Contactless Payments. (n.d.). Retrieved from http://www.smartcardalliance.org/publications-contactlesspayments-faq/

[10] Desk, I. (2016, August 27). Govt. announces list of first 20 smart cities under 'Smart Cities Mission'.

[11] Retrieved from www.thehindu.com: http://www.thehindu.com/news/national/list-of-first-20-smart-citiesunder-smart-cities-

mission/article8162775.ece?utm_source=InternalRef\&utm_medium=relatedNews\&utm_campaign=Relat edNews.

[12] Dimecres, \& Ancheta, J. (2014, February 26). Ten Reasons Why Barcelona is a Smart City. Retrieved fromhttp://www.vilaweb.cat/noticia/4175829/20140226/ten-reasons-why-barcelona-is-smart-city.html

[13] E-governance. (2016). Retrieved from https://en.wikipedia.org/wiki/E-governance

[14] Guerrini, F. (2015, February 18). The Future Of Agriculture? Smart Farming. Forbes.Honeywell | Building Solutions. (n.d.). Retrieved from buildingsolutions.honeywell.com: https://buildingsolutions.honeywell.com/en-US/solutions/intelligentbuildings/Pages/default.aspx 
[15] How the Smart Car Works. (n.d.). Retrieved from http://auto.howstuffworks.com/smart-car2.htmIntel. (2014). Designing More Affordable Smart Building Solutions. Retrieved from www.intel.com: http://www.intel.com/content/www/us/en/internet-of-things/designing-more-affordable-smart-buildingsolutions-brief.html

[16] JEELANI, M. (2015, August 28). Centre unveils list of 98 smart cities; UP, TN strike it rich. Retrieved fromTheHindu.com: http://www.thehindu.com/news/national/centre-releases-list-of-98-cities-for-smartcityproject/article7586751.ece?utm_source=InternalRef\&utm_medium=relatedNews\&utm_campaign=Relate dNews

[17] JOSHI, A. A. (2008). Advantages of E-Governance. Retrieved fromhttp://indiaegovernance.blogspot.in/2008/03/advantages-of-e-governance.html

[18] Khanna, P., Najib, R., \& Varma, G. (2016, January 29). India launches its urban makeover plan with smartcities. Retrieved from www.livemint.com:http://www.livemint.com/Politics/KY8pnCzuu370FchYHcPBgJ/Names-of-first-20smart-cities-in-India-to-be-announced-toda.html

[19] Kosir, S. (2015, April 15). Wearables in Healthcare. Retrieved from https://www.wearabletechnologies.com/2015/04/wearables-in-healthcare/

[20] Larson, S. (2015, January 4). Inside Amsterdam's efforts to becomne a smart city. The Kernel.LiveMint. (2016, January 29). Smart cities: The first 20. Retrieved from www.livemint.com: http://www.livemint.com/Politics/eER1ilL9HJY6QF5k2skS3J/Smart-cities-the-first-20.html

[21] MOUD. (2015, June 25). Criteria for selection of potential smart cities announced -Only capable cities tobe chosen through two stage competition. Retrieved from pib.nic.in:http://pib.nic.in/newsite/PrintRelease.aspx?relid=122782

[22] MOUD. (2015, June). Smart City - mission statements \& guidelines. Retrieved from Smartcities.gov.in:http://smartcities.gov.in/writereaddata/smartcityguidelines.pdf

[23] MOUD. (2015). The Process of Selection of Smart Cities. Retrieved from smartcities.gov.in:http://smartcities.gov.in/writereaddata/Process\%20of\%20Selection.pdf

[24] Peacock, L. (2015, November 13). Toronto one of 10 'smart cities' to launch IoT partnership.

[25] Smart Agriculture. (n.d.). Retrieved from https://www.thingworx.com/ecosystem/markets/smartconnected-systems/smart-agriculture/

[26] TANNERT, C. (2014, August 1). 10 Autonomous Driving Companies To Watch. FAST COMPANY.The benefits of Contactless. (n.d.). Retrieved from http://www.theukcardsassociation.org.uk/: http://www.theukcardsassociation.org.uk/contactless_consumer/the_benefits_of_contactless.asp

[27] UKTI. (2015, September). India's smart cities programme - The UK offer to build together. Retrieved fromgov.uk/ukti:https://www.gov.uk/government/uploads/system/uploads/attachment_data/file/460151/U KTI_-_The_UK_offer_to_build_together 1_.pdf

[28] Viereckl, R., Ahlemann, D., Koster, A., \& Jursch, S. (2015). Connected Car Study 2015: Racing ahead withautonomous cars and digital innovation. PWC.

[29] Visiongain. (2015). Top 20 Mobile Health (mHealth) Companies 2015 Innovators in Mobile Fitness, Telemedicine, eHealth \& Remote Patient Monitoring. London.

[30] Walt, V. (2015, July 29). Barcelona: The most wired city in the world. Fortune. 